\title{
Tax-Return Screening Inefficiency of the Internal Revenue Service: What can be done to Increase Compliance and Detection of Erroneously Claimed Educational Credits?
}

\author{
Valeriya Avdeev ${ }^{1 *}$, Sia Nassiripour ${ }^{2}$ \\ ${ }^{1,2}$ Accounting and Law Department, Cotsakos College of Business \\ William Paterson University, United States \\ *Corresponding author's email: AVDEEVV [AT] wpunj.edu
}

\begin{abstract}
On January 31 ${ }^{\text {st }}$, 2018, Treasury Inspector General for Tax Administration (TIGTA) issued a report examining the effectiveness of the agency specifically under the 2017 Tax Filing Season. The report is referenced as 2018-40-012. According to the report, during 2017 tax filing season, billions of dollars in potentially erroneous American Opportunity Tax Credits Continue to be issued. As noted in the TIGTA report, $1.2 \%$ of the returns filed during 2017 tax season contained an error and resulted in improper refunds due to American Opportunity Tax Credit error alone. This is a significant error on the part of the Internal Revenue Service that creates inefficiency and under-collection of revenue. This paper will identify possible solutions to the issue that could increase in the revenue as much as \$2.8 billion on annual basis
\end{abstract}

\section{INTRODUCTION}

On January $31^{\text {st }}, 2018$, Treasury Inspector General for Tax Administration (TIGTA) issued a report examining the effectiveness of the agency specifically under the 2017 Tax Filing Season. The report is referenced as 2018-40-012. According to the report, during 2017 tax filing season, billions of dollars in potentially erroneous American Opportunity Tax Credits Continue to be issued. ${ }^{1}$

American Opportunity Tax Credit is a partially refundable for undergraduate college student expenses that is only available for the first four years of undergraduate education. ${ }^{2}$ The credit is phased-out for single taxpayers with MAGI of $\$ 80,000$ or $\$ 160,000$ if married filing jointly. ${ }^{3}$ Specifically, TIGTA found that Internal Revenue Service continues to not effectively identify potentially erroneous American Opportunity Tax Credit claims before refunds are paid. ${ }^{4}$ As noted in the TIGTA report, 1.2\% of the returns filed during 2017 tax season contained an error and resulted in improper refunds due to American Opportunity Tax Credit error alone. This is a significant error on the part of the Internal Revenue Service that creates inefficiency and under-collection of revenue. By identifying possible solutions to this problem, an increase in the revenue of as much as $\$ 2.8$ billion can be created for the agency on annual basis. This issue is specifically of interest to William Paterson University as an educational institution that issues close to 10,000 1098-T forms every year to its students.

\section{ERRORS NOT DETECTED UPON FILING}

According to the report, billions of dollars in potentially erroneous American Opportunity Tax Credits continue to be issued and paid by the Internal Revenue Service. ${ }^{5}$ The report identified four errors that existed with AOTC tax return filings that were not identified or detected. ${ }^{6}$

First, even though the agency has the power to deny acceptance of the returns that are missing necessary EIN numbers, it appears that returns were nonetheless accepted that did not report an institutional EIN on Form 8863, Educational Credits. ${ }^{7}$ As evidenced by the report, even though PATH ACT section 211 requires taxpayers to include EIN of the educational institution on Form 8863, 16.2\% of the returns that were filed did not list an

\footnotetext{
${ }^{1}$ TIGTA, Results of the 2017 Filing Season, Ref. Number: 2018-40-012, January 31, 2018, p. 15.

${ }^{2}$ https://www.thebalance.com/american-opportunity-tax-credit-3193001

${ }^{3}$ Id.

${ }^{4}$ TIGTA, Results of the 2017 Filing Season, Ref. Number: 2018-40-012, January 31, 2018, p. 15.
}

${ }^{5} / d$.
${ }^{6} / d$.
${ }^{7} / d$. 
institutional EIN on Form $8863 .^{8}$ The amount of erroneous credits attributable to this deficiency was $\$ 1.9 \mathrm{M} .{ }^{9}$

Second, many credits that were paid out undetected were paid to students who claimed AOTC for more than four years. ${ }^{10}$ According to the report, 612,707 tax returns were filed in 2016 tax filing period, where students claimed the deduction beyond four years. ${ }^{11}$ Specifically, the American Recovery and Reinvestment Act of 2009 allows AOTC to be claimed for the first four years of postsecondary education. ${ }^{12}$ However, $7.7 \%$ of number of the returns that contained AOTC and those that were approved contained students who claimed the above-referenced credit beyond four years. ${ }^{13}$ The amount of erroneous credits attributable to this deficiency was $\$ 1 \mathrm{M} .{ }^{14}$

Third, the largest amount of erroneously approved AOTC claims were attributed to claims without Form 1098-T. ${ }^{15}$ Once again, the agency had the power to refuse the acceptance of these returns, but failed to do so. ${ }^{16}$ Specifically, the Trade Preferences Extension Act of 2015 requires a statement to be received from the educational institution. ${ }^{17}$ Precisely, for AOTC, such statement is Form 1098-T, Tuition Statement. However, in nearly 30\% of the erroneously claimed AOTC, no Form 1098-T was provided to support the student's claim of attending a postsecondary education institution. ${ }^{18}$ The amount of erroneous credits attributable to this deficiency was $\$ 3.6 \mathrm{M} .{ }^{19}$

Finally, the remaining erroneously-claimed AOTC was attributed to returns where the students did not meet the requirements of the credit. ${ }^{20}$ Namely, credit was applied to students who attended their educational institution only half-time or were graduate students as per their respective 1098 -T. ${ }^{21}$ Once again, the agency had the power to refuse the acceptance of these credits under the Taxpayer Relief Act of 1997 that required that the student enrollment under the credit had to be at least half-time. ${ }^{22}$ Moreover, the American Recovery and Reinvestment Act of 2009 allows AOTC to be claimed for postsecondary education only. ${ }^{23}$ However, in nearly $6 \%$ of the erroneously claimed credit, 1098-T listed the students as being enrolled half-time or being a graduate student. ${ }^{24}$ The amount of erroneous credits attributable to this deficiency was $\$ 0.7 \mathrm{M} .{ }^{25}$

\section{POSSIBLE SOLUTIONS}

After examining the four deficiencies listed above, TIGTA proposed various solutions needed to address the issue at hand. Specifically, in the report, it was stated that IRS does not have the authority needed to deny some of these erroneous AOTC claims at the time the returns are filed and processed. ${ }^{26}$ As such, TIGTA suggested that IRS must audit these tax returns. ${ }^{27}$ It was also recommended in the report that IRS revised its examination filters to identify students who had received AOTC for four years prior to the current tax return. ${ }^{28}$ In addition, the report stated that IRS, in conjunction with the Assistant Secretary of the Treasury for Tax Policy, had proposed a legislative proposal requesting additional authority under a new category of "correctable error" as part of its annual budget. ${ }^{29}$ The report also pointed out that Forms 1098-T are not available to the IRS at the time of the tax return filings since education institutions are not required to provide Forms 1098-T to the IRS until March 31 of any given year. ${ }^{30}$ As such, IRS does not have the necessary forms at the time the tax returns are filed and cannot verify the student's eligibility at

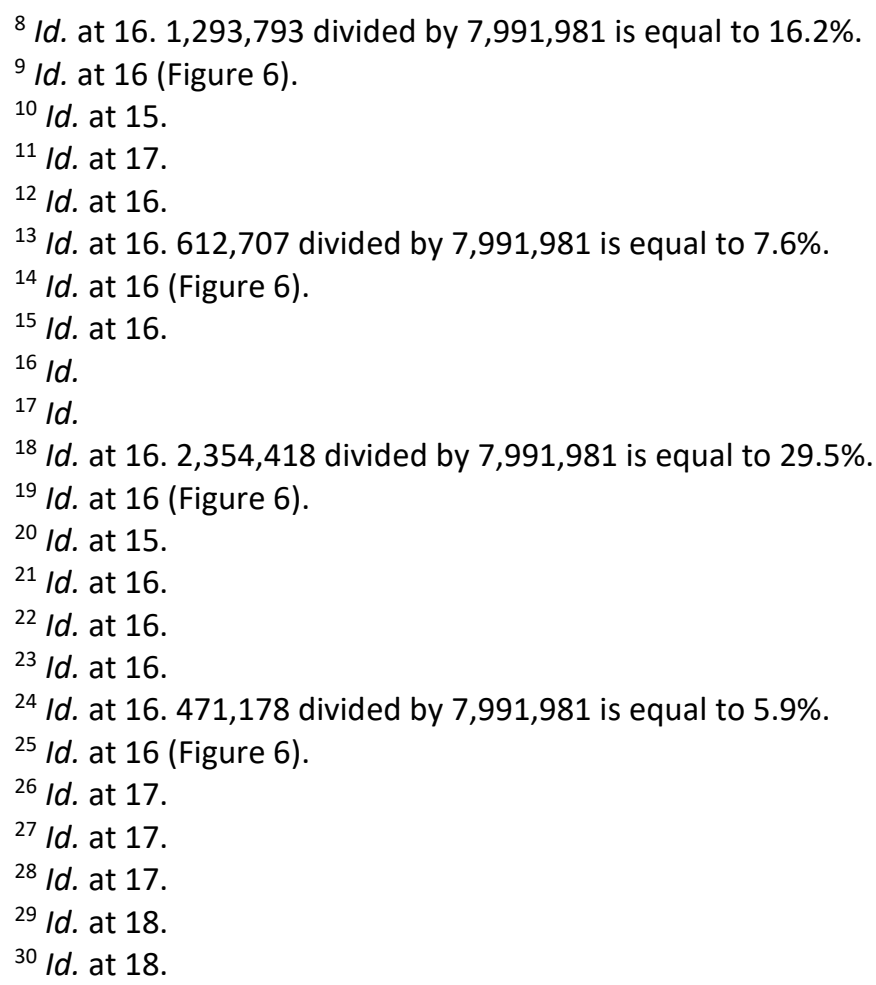


the time on filing. ${ }^{31}$ Clearly, earlier access to Forms 1098-T would improve the agency's ability to identify AOTC claimed incorrectly. ${ }^{32}$ As the result, TIGTA recommends to move the required submission date for Forms 1098 -T from March $31^{\text {st }}$ to January $31^{\text {st }} .{ }^{33}$ Another suggestion made in the report is to scan the AOTC claims based on the age of the student. ${ }^{34}$ Namely, students under the age of 16 and over the age of 75 are unlikely to attend a postsecondary education institution. ${ }^{35}$ Finally, the report strongly suggested to use math error authority to deny all efiled and paper tax returns that do not provide an EIN for the education institution. ${ }^{36}$

\section{CONCLUSION}

TIGTA found that Internal Revenue Service continues to not effectively identify potentially erroneous American Opportunity Tax Credit claims before refunds are paid. ${ }^{37}$ As noted in the TIGTA report, $1.2 \%$ of the returns filed during 2017 tax season contained an error and resulted in improper refunds due to American Opportunity Tax Credit error alone. This is a significant error on the part of the Internal Revenue Service that creates inefficiency and undercollection of revenue. By identifying possible solutions to this problem, an increase in the revenue of as much as $\$ 2.8$ billion can be created for the agency on annual basis. This issue is specifically of interest to William Paterson University as an educational institution that issues close to 10,000 1098-T forms every year to its students.

\footnotetext{
${ }^{31} / d$. at 18.

32 Id. at 19.

33 Id. at 19.

34 Id. at 19.

35 Id. at 19.

36 Id. at 20.

${ }^{37}$ TIGTA, Results of the 2017 Filing Season, Ref. Number: 2018-40-012, January 31, 2018, p. 15.
} 